Asia Pacific Journals

\title{
ANALYSIS OF TEMPERATURE AND THERMAL STRESSES IN FUNCTIONALLY GRADED DIESEL ENGINE VALVE
}

\author{
Subodh Kumar Sharma \\ Department of Mechanical Engineering, \\ Krishna Institute of Engineering \& Technology, \\ Ghaziabad, UP, India
}

\author{
P. K. Saini, Punit Kumar \\ Department of Mechanical Engineering, \\ National Institute of Technology, \\ Kurukshetra, Haryana, India
}

\begin{abstract}
-
MgZrO3 and NiCrAl based coatings are mostly used because of their higher properties such as low thermal conductivity, high hardness, oxidation resistance, chemical and thermal stability at cryogenic and high temperatures. These properties build them useful for many applications, including thermal barrier coatings (TBCs) on metallic substrates used at high temperatures in the fields of aircraft and aerospace, especially for thermal protection of components in gas turbines and diesel engine. In diesel engine high temperature flue gases come in direct contact of valve so the rate of heat transfer through valve is a critical parameter. Due to such high temperature inside the engine, thermal stresses are developed in the valve. In this paper our main aim is to increase performance of valve which is made by using functionally graded material coating. This coating consist two materials like NiCrAl and MgZrO3 which is done on substrate material (steel) and coating thickness kept constant. Temperature and thermal stress analysis are performed for different coating compositions of $\mathrm{NiCrAl}$ and $\mathrm{MgZrO3}$ without considering the effect of radiation. Effects of the coating composition on temperature field, thermal stress field and deformation are investigated theoretically; including comparisons with results from an uncoated valve by means of the finite element method. In the study it was found that Temperature at the coated surface is significantly higher than that of the uncoated valve surface so as to allow for higher operating temperature to increase thermal efficiency or reduce fuel consumption of engines makes to achieve higher compression ratios.
\end{abstract} TBC.

Keywords-Combustion component; Engine valve, FEM,

\section{INTRODUCTION}

Intake and exhaust valves are very important engine components that are used to control the flow and exchange of gases in internal combustion engines. They are used to seal the working space inside the cylinder against the manifolds; and are opened and closed by means of what is known as the valve train mechanism. Such valves are loaded by spring forces and subjected to thermal loading due to high temperature and pressure inside the cylinder. Internal combustion engine valves are precision engine components. They open and close as and when needed. The fresh charge (air - fuel mixture in Spark Ignition Engines and air alone in Compression Ignition Engines) is induced through inlet valves and the products of combustion get discharged to atmosphere through exhaust valves. They are also used to seal the working space inside the cylinder against the manifolds. There are different types of valves used by the manufactures; some common types of valves being poppet valves, slide valves, rotary valves and sleeve valve. Any type of valve failure affects the engine performance thus making it mandatory to give due importance to temperature and stress analysis of IC valves.

$\mathrm{MgZrO} 3$ and NiCrAl based coatings are broadly used because of their superior properties such as low thermal conductivity, and oxidation resistance, high hardness, chemical and thermal stability at cryogenic and high temperatures These properties make them useful for many applications, including thermal barrier coatings (TBCs) on metallic substrates used at high temperatures in the fields of aircraft and aerospace, especially for thermal protection of components in gas turbines and diesel engine. Thermal barrier coatings (TBCs) are commonly applied to substrates to insulate them thermally so as to allow for higher operating temperature to increase thermal efficiency or reduce fuel consumption of engines makes toachive higher compression ratios, for diesel engines, and reduced heat rejection from inside the cylinder TBCs permit working fluid temperatures higher than the melting point of the metal airfoil in some turbine applications. The objective of this paper is Evaluation of stresses in diesel engine valve made of Functional Graded Material (FGM) using Finite Element Method (FEM).In materials science functionally graded material (FGM) may be characterized by the variation in composition and structure gradually over volume, resulting in corresponding changes in the properties of the material. The materials can be designed for specific function and applications TBCs are mostly fails at the ceramic top coat from the bond coat and there are many factors that influence the overall performance of coatings and cause miscarriage of the coating. However, oxidation and thermal mismatch are identified as two major factors influencing the life of the coating system. There is bond coat layer which is used between the TBC and the metal substrate. The bond coat material is an intermetallic alloy that provides oxidation resistance at high temperatures and supports adhesion of the TBC layer to the substrate. The bond coat shows an important role in dropping the internal stresses which may ascend between the substrate and the ceramic coating because of thermal shock. The coefficient of thermal expansion of the bond coat should be between that of the TBC and the metal substrate. 


\section{Asia Pacific Journals}

\section{LITERATURE REVIEW}

The study of previous works always is the first stepping stone to every research in any particular field. This section deals with the elaborate analysis of related research papers and publications for an initial knowledge base for the analysis of the temperature field in a valve, piston and cylinder wall. A large number of research papers have been read out. A study is performed on piston head modeling, experimental study of the piston head and experimental study of the cylinder head fuelled with different mixtures ( E5, E10, E15) by Krisztina Uzuneanu et al. (2009) [1] . he found that a lower polytropic exponent of compression which results in lower pressures and temperatures and the mean thermal stress of the spark ignition engine is lower when using E10 then gasoline in the same engine operating conditions. C.D. Rakopoulos et al. (1996) [2] describes the development of a model for the calculation of the temperature field and heat flow in the combustion chamber components of internal combustion piston engines, which occur both under steady and transient engine operating conditions. A satisfactory degree of agreement is found between theoretical predictions and experimental data proving the validity of the analysis at the expense of a reasonable computational cost. L. H. You et al. (2005) [3] presented an accurate method to carry out elastic analysis of thick-walled spherical pressure vessels subjected to internal pressure. author found that an almost constant circumferential stress which significantly reduces the maximum value of the stress can be achieved. Sburlati (2012) [4] focuses to analyze the influence on the deformation of different through-thethickness variation laws of Young's modulus in FGMs thickwalled cylinders in pressure, by considering power and exponential laws. Ekrem Buyukkaya et al. (2007) [5], R. Mikalsen et al. (2008) [6] and Muhammet Cerit et al. (2011) [8] worked to investigate thermal analyses on a conventional (uncoated) diesel piston, made of aluminum silicon alloy and steel further thermal analyses are performed on pistons, coated with $\mathrm{MgO}-\mathrm{ZrO} 2$ material by means of using a commercial code, namely ANSYS. Finally, the results of four different pistons are compared with each other. Effects of varying engine stroke length and compression ratio were not found to give any large advantages.

The work based on instantaneous local heat transfer coefficient in spark-ignition engines was done by $\mathrm{A}$. Mohammadi et al. (2010) [7]. He found that with increasing engine speed the values of nusselt and reynolds numbers increase. E. Abu-Nada et al. (2006) [9] worked on Thermodynamic modelling of spark-ignition engine: Effect of temperature dependent specific heats and it is concluded that engine working parameters are affected by variable specific heats, significantly. The results show that there is a great effect of the temperature dependent specific heat of the working fluid on the performance of the air-standard Otto cycle. Therefore, it is more realistic to use temperature dependent specific heat during the investigation of airstandard power cycles. C.D. Rakopoulos et al. (2010) [10] worked on evaluation of current heat transfer models used in CFD in cylinder Engine simulations and establishment of a comprehensive wall-function formulation. A new heat transfer formulation has been derived, based on widely used existing ones and mainly on the original law-of-the-wall developed by Launder and Spalding.

M. Shalevet al. (1983) [11] worked experimentally and theoretically to investigate the mechanism of crack development in cylinder heads of two-stroke diesel engines and find that the phenomenon of crack development is related to the mechanism of "low cycle thermal fatigue" induced by starting, loading and shutting off of the engine. Sharma et al. (2012) [12] analyze the thermal stress distribution of ceramiccoated pistons, and found that he wavelet finite-element method had a faster convergence speed than the traditional finite-element method and could achieve greater numerical computational precision than the traditional finite-element method. Sharma et al. (2011) [13], Thet T. Mon et al. (2011) [14], M. Hahn et al. (2009) [14] and Sharma et al. (2009) [15] documents the results of a finite element analysis for the prediction of the steady state temperature distribution in a high speed diesel engine piston. The commercially available package used for the analysis is MSC/NASTRAN. An axisymmetric model neglecting temperature differences in the circumferential direction was analyzed. The result shows good correlations between predicted and measured temperatures. K. Kokini et al. (1993) [16] worked on Thermal Fracture Mechanisms in Ceramic Thermal Barrier Coatings and found that that the design of a TBC is a complex process that has to consider the thermal loading and other conditions that can be vastly different from one application to another. On the other hand, since the function of a TBC is to protect metallic substrates from high temperatures, the thermal resistance of the coating is also an important consideration.

\section{PROBLEM STATEMENTS}

From the previous study it was found that by using thermal barrier coatings of various compositions on piston it's performance improved and overall efficiency of the diesel engine increases. Hence, we choose to analyse the effect of coatings on valve. This will increase the knowledge about the way to find the suitable composition for the coating. The completion of the study comprises of five steps which are as follows:-Selection of the Diesel Engine Valve for study, Find the boundary conditions, Meshing of the valve diagram, Selection of composition materials for coating, FEM analyses and analyze the result.

\section{A. Kirloskar Engine has been used with following specifications: RPM-1500, Power - 3.7 kW, Brake Horse Power-5hp.}

\section{B. Diesel engine valve has been used with following specifications: Material : Steel, Length : 110mm, Stem diameter: $7 \mathrm{~mm}$, Head diameter: 30mm.}

For the determination of temperature and stress on different points, we have used Finite Element Method. For the analysis we have divided the valve into 89 nodes. The shape of an element is taken as triangular because it occupies very less area as compared to geometrical shape element like Quadra. The temperatures and stress at all the nodes are found and the results are drawn to find the best composition for coating. 
Asia Pacific Journals

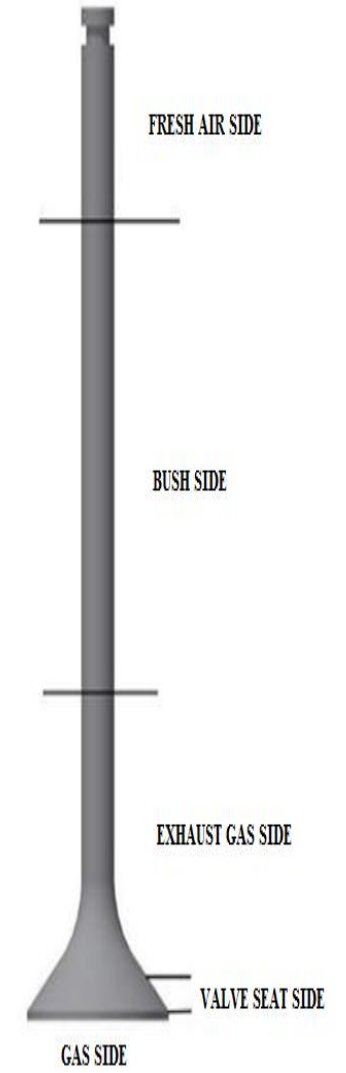

VALVE IIIHOUT COATIIG

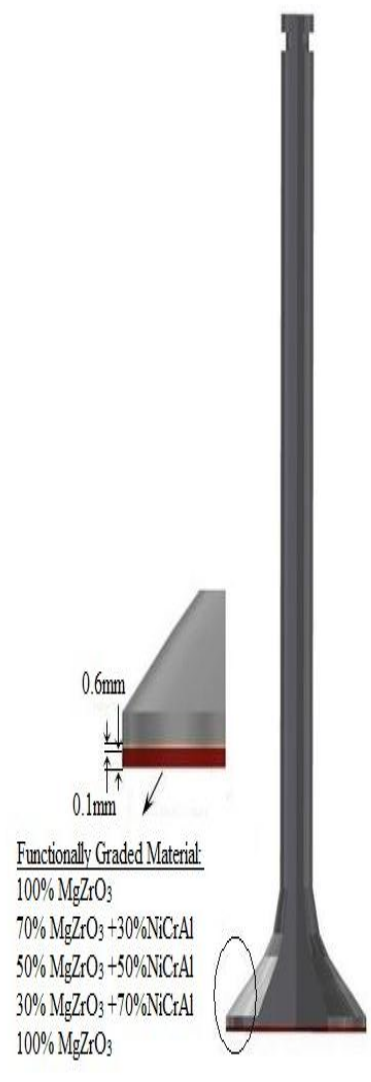

VALIE WITHH COATING
Fig. 1. Valve diagram without and with coating

The table 4.1 shows the nodal coordinates $(r, z)$ at every node. This data had been input into the coding language for the output. The nodes with the $\mathrm{r}$ and $\mathrm{z}$ are shown in the table. ' $r$ ' is the radial distance of each node from the central axis ( $Y$ axis) and $\mathrm{z}$ is depth of each node from the base (X-axis). Room temperature is assume as $27^{\circ} \mathrm{C}$.

\section{RESULT AND DISCUSSION}

In the substrate material distribution of temperature, which may cause deformation and change in property of material, versus radial distance for various composition of $\mathrm{NiCrAl}$ and $\mathrm{MgZrO}_{3}$ are plotted in Fig. 2. All of the temperature curves are nearly parallel with each other but their temperature value is different. The minimum temperature value is $418.89,418.86$, $418.82,418.72,418.10,417.68^{\circ} \mathrm{C}$, for the radius of $0,3.5,5,7$, $12,15 \mathrm{~mm}$ respectively, for the composition of $100 \% \mathrm{MgZrO} 3$ which is suitable for us. At the bond coat surface, distribution of temperature versus radial distance for various compositions of $\mathrm{NiCrAl}$ and $\mathrm{MgZrO} 3$ are plotted in Fig. 3. All the temperature curves are parallel and especially close to each other for other composition of $\mathrm{NiCrAl}$ and $\mathrm{MgZrO} 3$ except $100 \% \mathrm{MgZrO} 3$ but their temperature values are different. The minimum temperature value is $419.83,419.61,418.75^{\circ} \mathrm{C}$ at the radius of $0,7,15 \mathrm{~mm}$ respectively for $100 \% \mathrm{MgZro} 3$ which is best from temperature point of view.

At the TBC, distribution of temperature versus radial distance for various compositions of $\mathrm{NiCrAl}$ and $\mathrm{MgZrO} 3$ are plotted in Fig. 4. All the temperature lines are parallel to each other but their temperature values are different.

Generally temperature below TBC should be high to get high efficiency and according to our analysis our best suited material is $100 \% \mathrm{MgZrO} 3$ which have temperature of 508.88, $508.44,514.22^{\circ} \mathrm{C}$ at the radius of $0,7,15 \mathrm{~mm}$ respectively for $100 \% \mathrm{MgZrO} 3$ which is far more than $30 \% \mathrm{NiCrAl}+70 \%$ $\mathrm{MgZrO} 3$.

The variation of the maximum temperature with the composition on substrate, bond coat and TBC surfaces are shown in Fig. 5. From temperature point of view it is clear that as the composition of $\mathrm{MgZrO} 3$ increases the temperature at TBC increases continuously and became maximum at $100 \%$ $\mathrm{MgZrO} 3$ and if we talk about substrate and bond coat then the temperature continuously decreases and became minimum at $100 \% \mathrm{MgZrO} 3$ which is desirable. The reason behind increased temperature at $\mathrm{TBC}$, decreased temperature at substrate and bond coat is its lower thermal conductivity.

At the substrate, distributions of radial stress, which may cause spalling of the coating, versus radial distance are plotted in Fig. 6. All the radial stress curves are similar in nature having different values. The stress value for $100 \% \mathrm{MgZrO}_{3}$ is $362.70,362.31,361.40,359.76,360.81,359.89 \mathrm{MPa}$ at the radial distance of $0,3.5,5,7,12,15 \mathrm{~mm}$ respectively.

At the bond coat surface, distributions of radial stress, which may cause spalling of the coating, versus radial distance are plotted in Fig. 7. For $100 \% \mathrm{MgZrO} 3$ the radial stress value is showing unfavorable result because after $7 \mathrm{~mm}$ radial distance the stress value is far more than the other stresses gained by some different composition. Hence $30 \%$ $\mathrm{NiCrAl}+70 \% \mathrm{MgZrO} 3$ showing better result than others having stress value $377.098,379.65$ and $380.56 \mathrm{MPa}$ for radial distance of 0,7 and $15 \mathrm{~mm}$ respectively.

At the TBC, distributions of radial stress, which may cause surface cracks in the coating, versus radial distance are plotted in Fig. 8. For $100 \%$ MgZrO3 the radial stress is very high due to higher temperature at TBC. Hence $30 \% \mathrm{NiCrAl}+70 \%$ $\mathrm{MgZrO} 3$ showing better result than others having stress value $390.23,385.16$ and $388.52 \mathrm{MPa}$ for radial distance of 0,7 and $15 \mathrm{~mm}$ respectively.

The variation of the maximum radial stress distribution with the composition on substrate, bond coat and TBC surfaces are shown in Fig. 12. It is clear from the figure that as we increase the composition of $\mathrm{MgZrO} 3$ the value of radial stress is continuously increasing at TBC and decreasing at substrate layer. Hence for $30 \% \mathrm{NiCrAl}+70 \% \mathrm{MgZrO} 3$, whose stress value is at moderate level in all layer, is showing better result than others. The variation of the maximum axial stress distribution with radial distance on substrate, bond coat and TBC surfaces are shown in Fig. 9, Fig. 10 and Fig. 11 whose values are different but nature is similar to radial stress distribution. 
Asia Pacific Journals

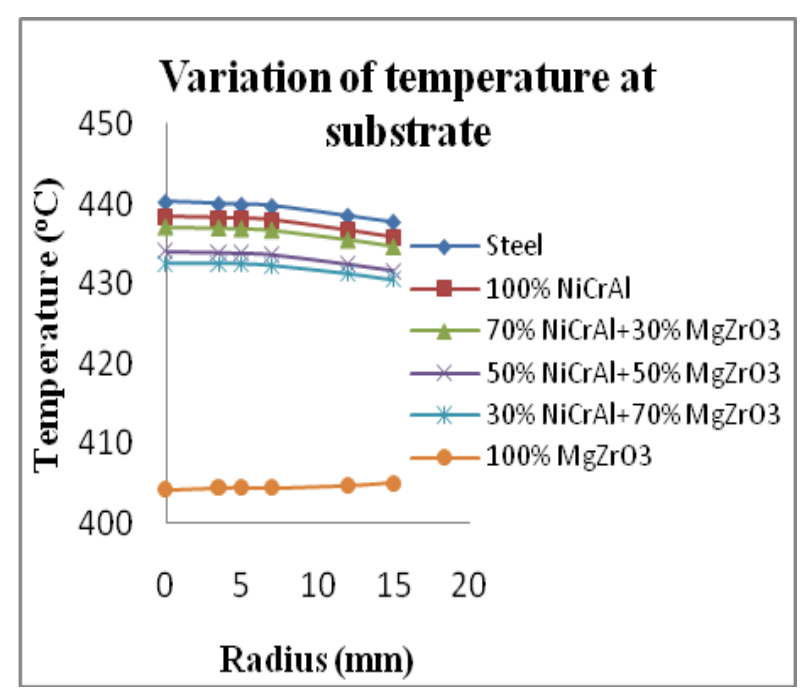

Fig. 2. Variation of temperature at substrate

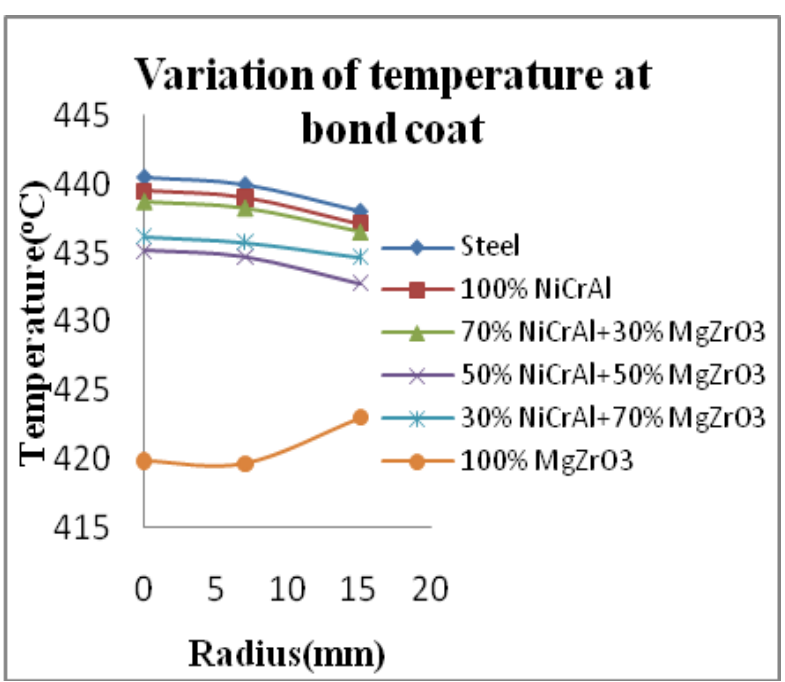

Fig. 3. Variation of temperature at Bond Coat

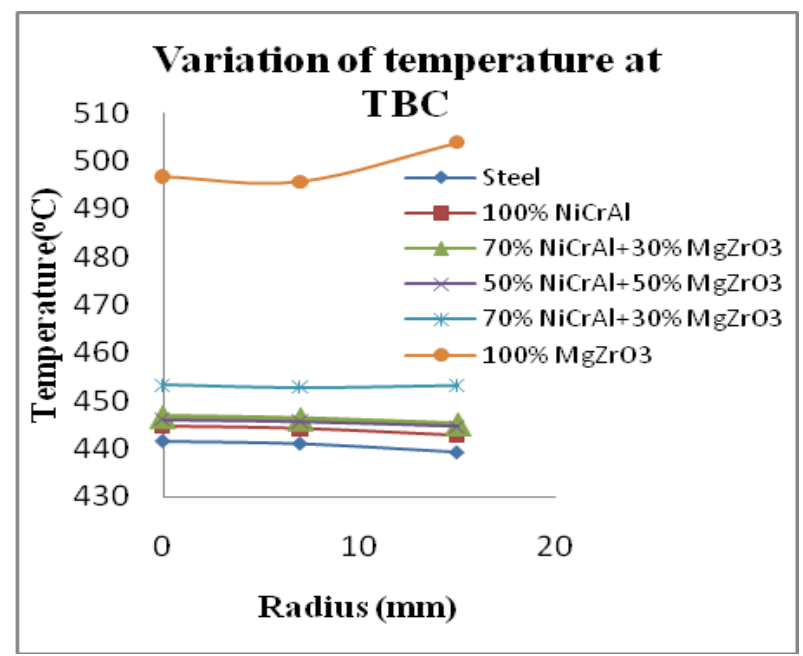

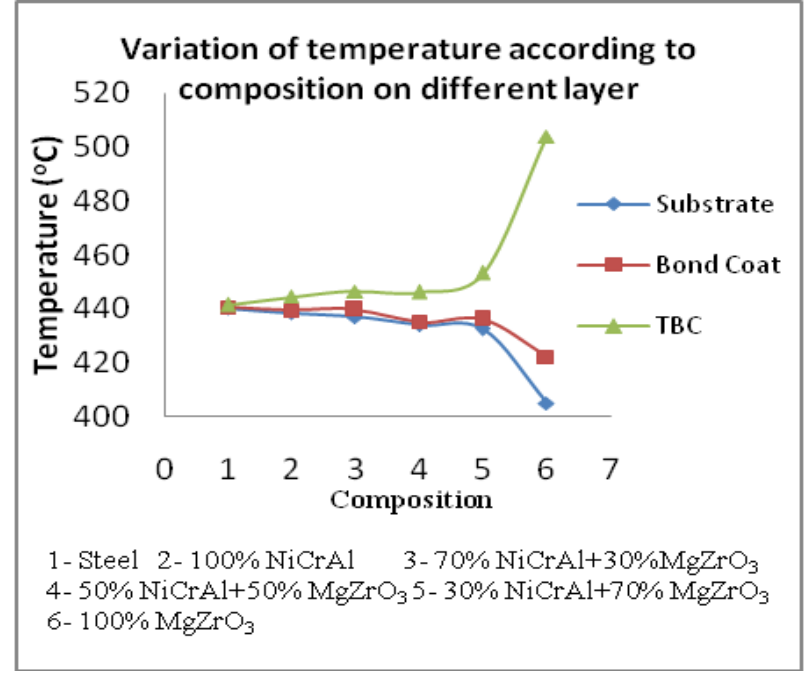

Fig. 4. Variation of temperature according to..Composition on different layer

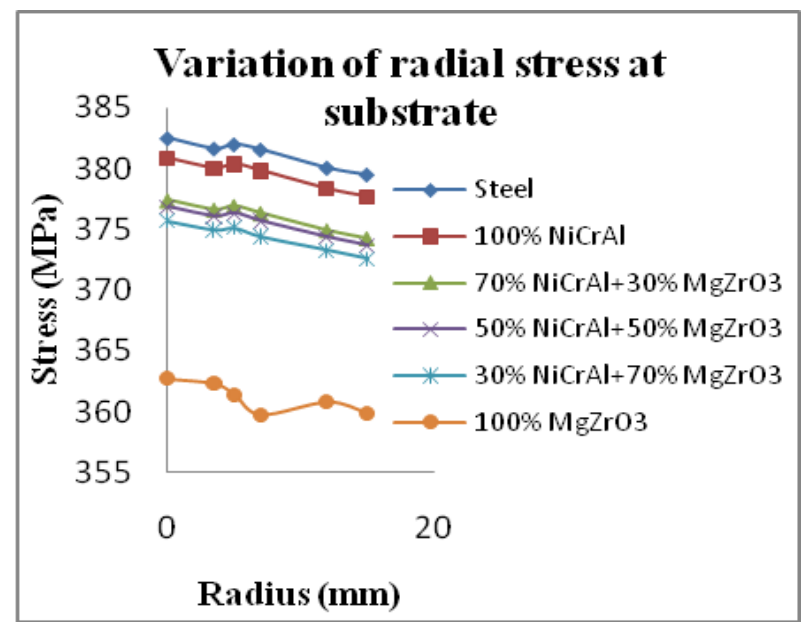

Fig. 5. Variation of radial stress at substrate

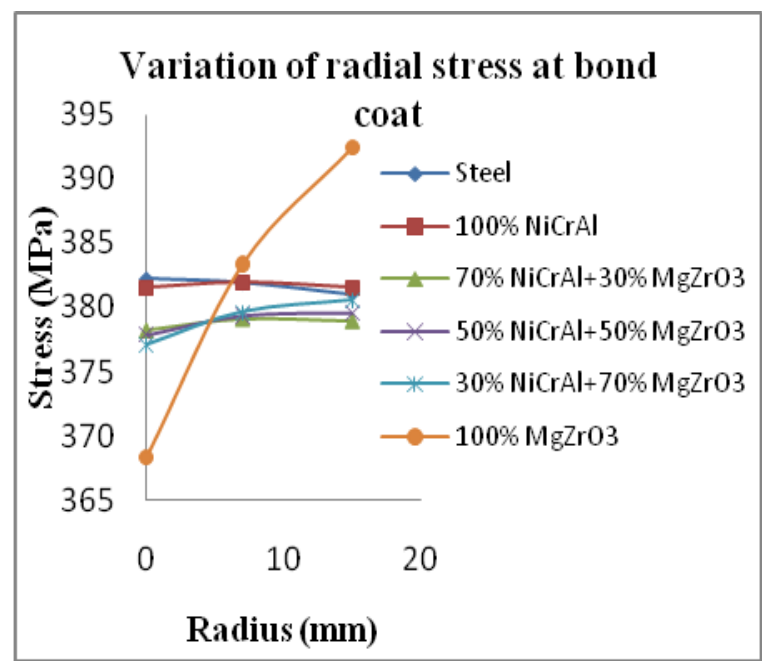


ELK

Asia Pacific Journals

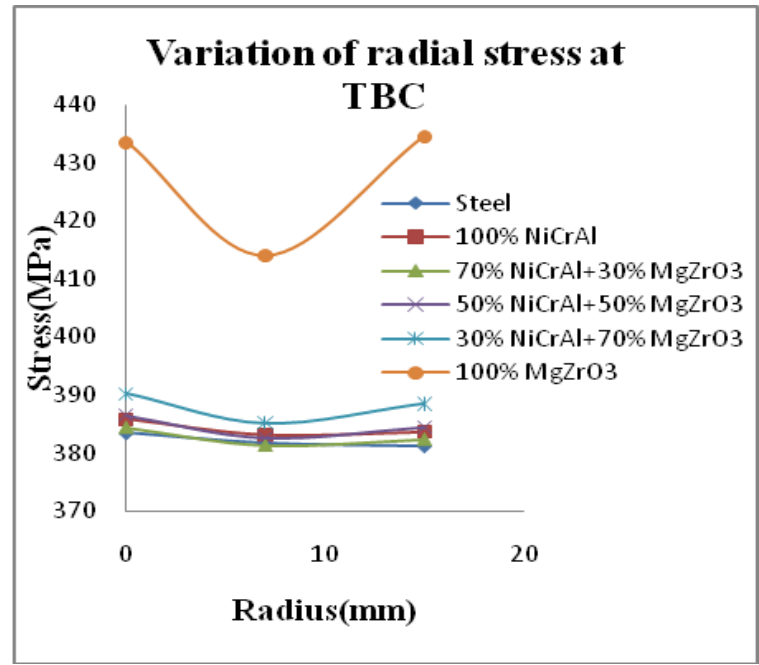

Fig. 6. Variation of radial stress at TBC

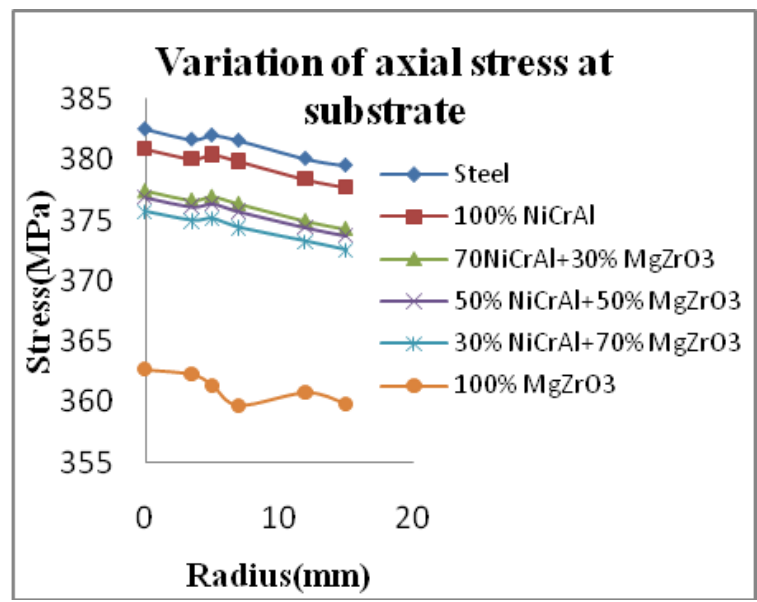

Fig. 7. Variation of axial stress at substrate

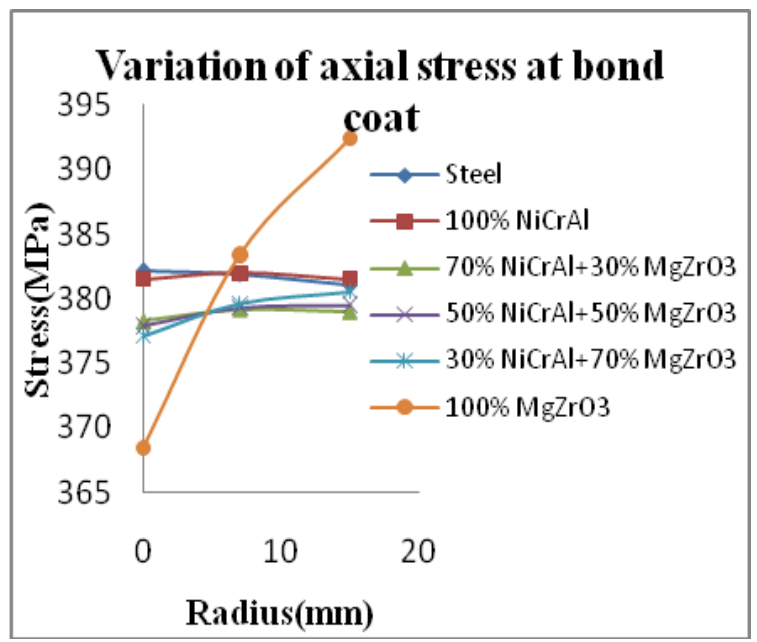

Fig. 8. Variation of axial stress at bond coat

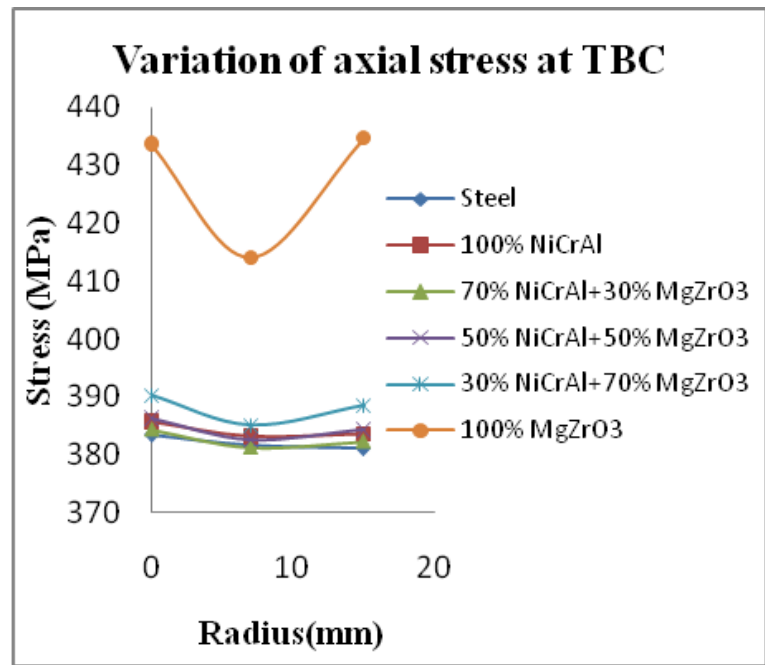

Fig. 9. Variation of axial stress at TBC

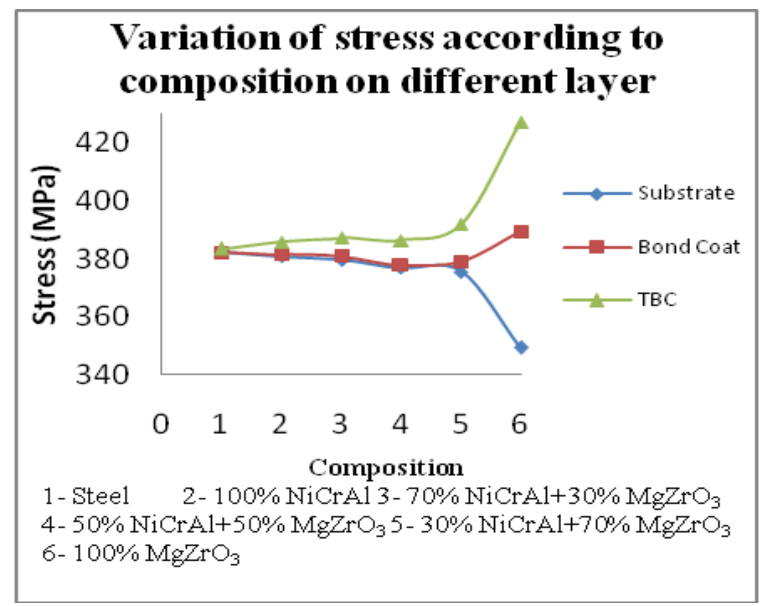

Fig. 10. Variation of stress according to composition .on different layer

TABLE I. VARIATION OF THERMAL CONDUCTIVITY WITH NODAL COORDINATES

\begin{tabular}{|c|c|}
\hline $\begin{array}{l}\text { Thermal conductivity } \\
\qquad\left(\mathbf{W} / \mathbf{m}^{\circ} \mathbf{K}\right)\end{array}$ & Composition \\
\hline 79 & All Cases \\
\hline 79 & uncoated steel valve \\
\hline 16.1 & for $100 \% \mathrm{NiCrAl}$ \\
\hline 16.1 & for $30 \% \mathrm{MgZrO} 3+70 \% \mathrm{NiCrAl}$ \\
\hline & \\
\hline \begin{tabular}{c|}
16.1 \\
7.3
\end{tabular} & for $50 \% \mathrm{MgZrO} 3+50 \% \mathrm{NiCrAl}$ \\
\hline $\begin{array}{l}16.1 \\
4.6\end{array}$ & for $70 \% \mathrm{MgZrO} 3+30 \% \mathrm{NiCrAl}$ \\
\hline $\begin{array}{l}16.1 \\
0.8\end{array}$ & $100 \% \mathrm{MgZrO} 3$ \\
\hline
\end{tabular}


TABLE II. BOUNDARY CONDITION ON DIFFERENT CROSS SECTION

\begin{tabular}{|l|c|c|}
\hline \multicolumn{1}{|c|}{ Parameter } & $\begin{array}{c}\text { Heat Transfer } \\
\text { Coefficient } \\
\left(\mathbf{w} / \mathbf{m}^{\mathbf{2}} \mathbf{k}\right)\end{array}$ & $\begin{array}{c}\text { Temperature } \\
\left({ }^{\mathbf{0}} \mathbf{C}\right)\end{array}$ \\
\hline FRESH AIR SIDE & 23 & 25 \\
\hline BUSH SIDE & 1745 & 80 \\
\hline EXHAUST GAS SIDE & 1775 & 290 \\
\hline VALVE SEAT SIDE & 2325 & 300 \\
\hline COMBUSTION SIDE & 290 & 1000 \\
\hline
\end{tabular}

\section{CONCLUSIONS}

Conclusions which we found from above discussion are listed below:-

From the temperature distribution curves, it is clear that temperature at the $\mathrm{TBC}$ is maximum and minimum at substrate for $100 \% \mathrm{MgZrO}$. Hence, from the temperature distribution it can be concluded that $100 \% \mathrm{MgZrO} 3$ composition is best and second best composition is $30 \%$ $\mathrm{NiCrAl}+70 \% \mathrm{MgZrO} 3$.

From the radial stress distribution curve it is clear the value of stress is increases as we move radially outward direction because material is lesser in this portion. So it is clear that, $100 \% \mathrm{MgZrO} 3$ is not suitable and radial stress for $30 \% \mathrm{NiCrAl}+70 \% \mathrm{MgZrO} 3$ is lesser at substrate hence from this case it can be concluded that $30 \% \mathrm{NiCrAl}+70 \%$ $\mathrm{MgZrO} 3$ is best.

From isotherm curves it is clear that as the percentage of $\mathrm{MgZrO} 3$ increases, heat transfer rate decreases for $100 \%$ $\mathrm{MgZrO} 3$, it is minimum and temperature at the TBC is maximum i.e. 510 OC. From all above conclusions, we can easily conclude that $30 \% \mathrm{NiCrAl}+70 \% \mathrm{MgZrO} 3$ is the composition which is feasible and can be selected for coating. It gives best result.

\section{References}

[1] K. Uzuneanu, T. Panait, D. Scarpete, "Computational modelling of thermal stresses in the combustion chamber of a spark ignition engine fueled with ethanol- gasoline blends", Tom 48, 2009, chapter 4.

[2] C. D. Rakopoulos, G. C. Mavropoulos, "Study of the steady and transient temperature field and heat flow in the combustion chamber components of a medium speed diesel engine using finite element analyses," International journal of energy research, vol. 20, 1996, pp. 437-464.

[3] L. H. You, J. J. Zhang, X. Y. You, "Elastic analysis of internally pressurized thick-walled spherical pressure vessels of functionally graded materials," International Journal of Pressure Vessels and Piping, vol. 82, 2005, pp. 347-354.

[4] R. Sburlati, "Analytical elastic solutions for pressurized hollow cylinders with internal functionally graded coatings," Composite Structures, vol. 94, 2012, pp. 3592-3600.

[5] E. Buyukkaya, M. Cerit, "Thermal analysis of a ceramic coating diesel engine piston using 3-D finite element method," Surface \& Coatings Technology, vol. 202, 2007, pp. 398-402.

[6] R. Mikalsen, A. P. Roskilly, "The design and simulation of a two-stroke free-piston compression ignition engine for electrical power generation," Applied Thermal Engineering, vol. 28, 2008, pp. 589-600.

[7] A. Mohammadi, M. Yaghoubi, "Estimation of instantaneous local heat transfer coefficient in spark-ignition engines," International Journal of Thermal Sciences, vol. 49, 2010, pp. 1309-1317

[8] Muhammet Cerit, "Thermo mechanical analysis of a partially ceramic coated piston used in an SI engine," Surface \& coatings technology, vol. 205, 2011, pp. 3499-3505.

[9] E. Abu-Nada, "Thermodynamic modeling of spark-ignition engine: Effect of temperature dependent specific heats," International Communications in Heat and Mass Transfer, vol. 33, 2006, pp. 1264 1272 .

[10] C. D. Rakopoulos, "Critical evaluation of current heat transfer models used in CFD in-cylinder engine simulations and establishment of a comprehensive wall-function formulation," Applied Energy, vol. 87, 2010, pp. 1612-1630.

[11] M. Shalev, Y. Zvirin and A. Stotter, "experimental and analytical analysis of the heat transfer and thermal stresses in a cylinder head of a diesel engine,” Int. J. Mech. Sci., vol. 25 (7), 1983, pp. 471-483.

[12] Subodh Kumar Sharma, P. K. Saini and N. K. Samria, "Computational Modeling of Temperature Field and Heat Transfer Analysis for the Piston of Diesel Engine with and without Air Cavity," Jordan Journal of Mechanical and Industrial Engineering," Vol. 9(2), 2015, pp 139 - 147.

[13] S. K. Sharma, P. K. Saini and N. K. Samria, "Experimental Thermal Analysis of Diesel Engine Piston and Cylinder Wall," The Journal of Engineering-Hindawi Publishing Corporation, 2015, Article ID 178652.

[14] Thet T. Mon, Rizalman Mamat and Nazri Kamsah, "Thermal analysis of SI-engine using simplified finite element method," Proceedings of the World Congress on Engineering, vol. III, 2011, pp. 978-988.

[15] S. K. Sharma, P. K. Saini and N. K. Samria, "Modelling and analysis of radial thermal stresses and temperature field in diesel engine valves with and without air cavity," International Journal of Engineering, Science and Technology, vol. 5(3), 2013, pp. 111-123.

[16] K. Kokini, B.D. Choules, and Y.R. Takeuchi,Thermal Fracture Mechanisms in Ceramic Thermal Barrier Coatings, journal of thermal spray technology. Volume 6 (1) (1993) 43-49. 